\title{
Pneumococcal Carriage Recovered from Healthy Children and Their Possible Association with Some Risk Factors in Outpatient Department of a 1000 bedded Tertiary Care Hospital at Dhaka City
}

\author{
Moonmoon Shormin ${ }^{1}$, SM Shamsuzzaman ${ }^{2}$, Md. Eunus Ali Mondol ${ }^{3}$, Samira Afroz $^{4}$, Asif Rashed ${ }^{5}$ \\ ${ }^{1}$ Assistant Professor, Department of Microbiology, City Medical College, Gazipur, Bangladesh; ${ }^{2}$ Professor, Head of the department, \\ Department of Microbiology, Dhaka Medical College, Dhaka, Bangladesh; ${ }^{3}$ Principal \& Professor, Department of Microbiology, \\ City Medical College, Gazipur, Bangladesh; ${ }^{4}$ Assistant Professor, Department of Microbiology, Shahab Uddin Medical College, \\ Dhaka, Bangladesh; ${ }^{5}$ Assistant Professor, Department of Microbiology, Jashore Medical College, Jashore, Bangladesh
}

[Received: 1 July 2019; Accepted: 15 September 2019; Published: 1 December 2019]

\begin{abstract}
Background: Detection and monitoring of nasopharyngeal carriage of Streptococcus pneumoniae is important to assess the impact and effectiveness of pneumococcal vaccine programs. Objective: The aims of this study were to assess the nasopharyngeal colonization rate, investigate some of the risk factors for nasopharyngeal colonization with S. pneumoniae from healthy children. Methodology: The study was conducted in the department of microbiology of Dhaka Medical College Hospital (DMCH). Data were collected among 200 under five healthy children in different age group (13 months to 36 months), from different socioeconomic status with cramped housing condition from Pediatric OPD of Dhaka Medical College Hospital. S. pneumoniae were isolated and identified by culture, Gram staining, biochemical test and polymerase chain reaction (PCR). Result: Out of 200 nasopharyngeal swabs, 67 (33.50\%) were found to be carriers positive by culture and $92(46 \%)$ by PCR. The carrier rate was higher among 13 months to 36 months, low and middle socio-economic groups and among with cramped housing condition. Conclusion: In conclusion various factors may affect the nasopharyngeal colonization with S. pneumoniae including early age of life, different socio-economic and living condition. [Bangladesh Journal of Infectious Diseases, December 2019; 6(2):48-52]
\end{abstract}

Keywords: Nasopharyngeal colonization; Streptococcus pneumoniae; risk factors; invasive pneumococcal diseases; pneumococcal vaccine

Correspondence: Dr. Moonmoon Shormin, Assistant Professor, Department of Microbiology, City Medical College, Gazipur, Bangladesh; Email: moonmoon.shormin@gmail.com; Cell no.: +8801711132920

Conflict of interest: There is no conflict of interest to any of the authors of this article.

Funding agency: The study was not funded by any authority.

Contribution to authors: Shormin M, Shamsuzzaman SM, Mondol MEA involved in protocol preparation, data collection and literature search up to manuscript writing., Afroz S, Rashed A involved in preparation and revision of this manuscript

How to cite this article: Shormin M, Shamsuzzaman SM, Mondol MEA, Afroz S, Rashed A. Pneumococcal Carriage Recovered from Healthy Children and Their Possible Association with Some Risk Factors in Outpatient Department of a 1000 bedded Tertiary Care Hospital at Dhaka City. Bangladesh J Infect Dis 2019;6(2):48-52

Copyright: (02019. Shormin et al. Published by Bangladesh Journal of Infectious Diseases. This article is published under the Creative Commons CC BY-NC License (https://creativecommons.org/licenses/by-nc/4.0/). This license permits use, distribution and reproduction in any medium, provided the original work is properly cited, and is not used for commercial purposes. 


\section{Introduction}

Streptococcus pneumoniae is a major cause of pneumonia, meningitis, and other invasive diseases resulting in high mortality and morbidity among children under the age of five, particularly in lower income countries ${ }^{1}$. The World Health Organization estimated that there are nearly one million deaths each year in children younger than five years of age and one child under five years of age dies because of pneumococcal pneumonia in every 20 seconds $^{2}$. Streptococcus pneumoniae is a bacterium that colonizes the nasopharynx of human and main source is person to person transmission ${ }^{3}$.

Streptococcus pneumoniae colonization is often asymptomatic but may cause overt infections. Community-acquired pneumonia (CAP) and infections of normally sterile sites (pleural fluid, cerebrospinal fluid and blood) are the most common infections by Streptococcus pneumoniae which are collectively called invasive pneumococcal disease ${ }^{4}$. It is spread by respiratory droplets and children are the main source of transmission to adults.

Universally, carriage rates are highest in young children (40.0 to $60.0 \%$ ), compared with older children $(12.0 \%)$, adolescents $(6.0$ to $10.0 \%)$ and adults (3.0 to $4.0 \%$ ) pathogenesis of invasive pneumococcal disease (IPD) begins with nasopharyngeal (NP) colonization that proceeds, often through local infection, to blood stream invasion ${ }^{5}$. Although almost all children become colonized with Streptococcus pneumoniae repeatedly during the first few years of life, a very small fraction of these acquisitions results in invasive disease. Colonization rates are higher $(>50.0 \%)$ in situation of overcrowding such as in day-care centers, orphanages, slums and in indigenous population ${ }^{6}$.

The aims of the study were to assess the nasopharyngeal colonization rate as well as to investigate the risk factors for colonization with Streptococcus pneumoniae for continuous monitoring of Streptococcus pneumoniae carriage for future pneumococcal vaccination program to prevent pneumococcal diseases.

\section{Methodology}

This cross sectional study was conducted in the Department of Microbiology of Dhaka Medical College Hospital (DMCH), Dhaka, Bangladesh. Nasopharyngeal swabs were collected from healthy children aged one month to less than five years who attended the outpatient department of DMCH for routine immunization, child growth monitoring and nutritional advice. Nasopharyngeal swabs were collected, labeled and placed immediately in one $\mathrm{ml}$ of skim milk-tryptone-glucose-glycerol (STGG) medium and transported to the laboratory. The NPS-STGG specimens were inoculated on blood

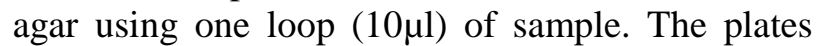
were streaked into four quadrants and incubated at $37^{\circ} \mathrm{C}$ for 24 hours with $\mathrm{CO}_{2}$ atmosphere inside a candle jar. Small, smooth and transparent colonies were seen on blood agar plate. Colonies were low convex, tiny and they became flattened centrally showing the 'draughtsman form'. A narrow zone of alfa hemolysis was seen around the colonies. Streptococcus pneumoniae were isolated and was identified. Gram positive diplococci were seen which were ovoid or lanceolate in shape as well as catalase negative. The isolates with presumptive identification were confirmed by optochin sensitivity test and bile solubility test. PCR was also done directly from nasopharyngeal swabs. Samples preserved in STGG medium were brought out from freeze and kept them at room temperature to demoisture and samples were vortexed to make a homogenous suspension. Then removed the swab sticks and the vortexed specimens were taken into two micro centrifuge tubes, labeled proper centrifuged at $10,000 \mathrm{Xg}$ for 10 minutes and the supernatant was discarded. The deposit was used as pellet for PCR. The micro centrifuge tubes containing pellet were kept at $-20^{\circ} \mathrm{C}$ until DNA extraction. During DNA extraction, two hundred micro litter of lytic buffer was mixed with the sample pellets and vortexed until mixed well. Then the tubes were incubated at $60^{\circ} \mathrm{C}$ for 3 hours. After incubation, tubes were kept in heat block at $100^{\circ} \mathrm{C}$ for 10 minutes for boiling. Then the tubes were immediately placed on ice for 5 minutes. After that the tubes were centrifuged at $4^{\circ} \mathrm{C}$ at $14000 \mathrm{X}$ g for 10 minutes. Finally supernatant was taken using micropipette and used as template DNA for PCR. This DNA was kept at $-20^{\circ} \mathrm{C}$ for future use ${ }^{7}$. The primer cpsA were used for targeted highly conserved gene that exists in all capsular loci thus far characterized ${ }^{8}$.

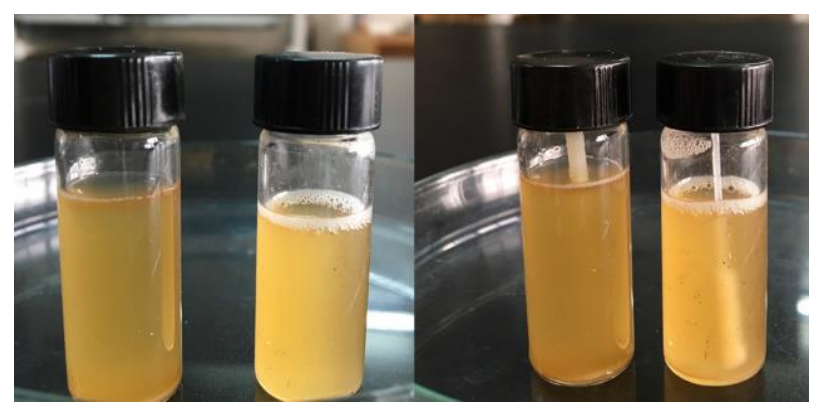

Figure I: STGG media and STGG media with swab 


\section{Results}

A total number of 200 cases under five children were tested and among them, 67(33.50\%) cases were positive for Streptococcus pneumoniae by culture and 92 (46\%) were positive by PCR (Table $1)$.

Table 1: Culture and PCR for Streptococcus pneumoniae from nasopharyngeal swabs $(n=200)$

\begin{tabular}{|l|c|c|}
\hline Methods & Frequency & Percent \\
\hline Culture positive & 67 & 33.5 \\
\hline PCR positive & 92 & 46.0 \\
\hline Not Positive & 41 & 20.5 \\
\hline
\end{tabular}

Out of 40 children in one month to 12 months age group, Streptococcus pneumoniae carriage was $13(32.50 \%)$ in culture and 21(52.50\%) in PCR. Among 65 children of 13 months to 36 months age group, Streptococcus pneumoniae carriage was $29(44.62 \%)$ in culture and 38(58.46\%) in PCR. Out of 95 children in 37 months to $\leq 60$ months age group, Streptococcus pneumoniae carriage was $25(26.32 \%)$ in culture and $33(34.74 \%)$ in PCR (Table 1).

Table 2: Results of Culture and PCR in Different Age Groups (n=200)

\begin{tabular}{|l|c|c|}
\hline Age Group & $\begin{array}{c}\text { Culture } \\
\text { Positive }\end{array}$ & $\begin{array}{c}\text { PCR } \\
\text { Positive }\end{array}$ \\
\hline 1 to 12 months & $13(32.50 \%)$ & $21(52.50 \%)$ \\
\hline 13 to 36 months & $29(44.62 \%)$ & $38(58.46 \%)$ \\
\hline 37 to $\leq 60$ months & $25(26.32 \%)$ & $33(34.74 \%)$ \\
\hline Total & $\mathbf{6 7}$ & $\mathbf{9 2}$ \\
\hline
\end{tabular}

Out of 63 children of low income group, Streptococcus pneumoniae carriage was $24(38.10 \%)$ in culture and 33(52.38\%) in PCR. Among 129 children of middle income group, Streptococcus pneumoniae carriage was $42(32.56 \%)$ in culture and $58(44.96 \%)$ in PCR. (Table 3).

Table 3: Streptococcus pneumoniae among Study Population in Different Socio-Economic Groups $(\mathbf{n}=200)$

\begin{tabular}{|l|c|c|}
\hline $\begin{array}{l}\text { Socio-economic } \\
\text { groups }\end{array}$ & $\begin{array}{c}\text { Culture } \\
\text { Positive }\end{array}$ & $\begin{array}{c}\text { PCR } \\
\text { Positive }\end{array}$ \\
\hline Low income & $24(38.10 \%)$ & $33(52.38 \%)$ \\
\hline Middle income & $42(32.56 \%)$ & $58(44.96 \%)$ \\
\hline High income & $1(12.50 \%)$ & $1(12.50 \%)$ \\
\hline Total & $\mathbf{6 7}$ & $\mathbf{9 2}$ \\
\hline
\end{tabular}

Among 117 cases, $32(27.35 \%)$ were culture positive and 37 (31.62\%) were PCR positive with family size below five. Out of 83 children, 35 $(42.17 \%)$ were culture positive and $55(66.27 \%)$ were PCR positive with family size above five. Out of 95 cases, $48(50.53 \%)$ were culture positive and $64(67.37 \%)$ were PCR positive with one room in their house. Among 105 cases, 19 (18.10\%) were culture positive and 28 (26.67\%) were PCR positive with two or more rooms in their house (Table 4).

Table 4: Culture and PCR Positivity among Study Population in Relation to Crowding Status $(\mathbf{n}=\mathbf{2 0 0})$

\begin{tabular}{|l|c|c|}
\hline Crowding Factors & $\begin{array}{c}\text { Culture } \\
\text { Positive }\end{array}$ & $\begin{array}{c}\text { PCR } \\
\text { Positive }\end{array}$ \\
\hline Family Size & $32(27.35 \%)$ & $37(31.62 \%)$ \\
\hline$<5(\mathrm{~N}=117)$ & $35(42.17 \%)$ & $55(66.27 \%)$ \\
\hline$\geq 5(\mathrm{~N}=83)$ & $\mathbf{6 7}$ & $\mathbf{9 2}$ \\
\hline Total & $48(50.53 \%)$ & $64(67.37 \%)$ \\
\hline Number of Room & $19(18.10 \%)$ & $28(26.67 \%)$ \\
\hline 1 & $\mathbf{6 7}$ & $\mathbf{9 2}$ \\
\hline$\geq 2$ & \multicolumn{2}{|l|}{} \\
\hline Total
\end{tabular}

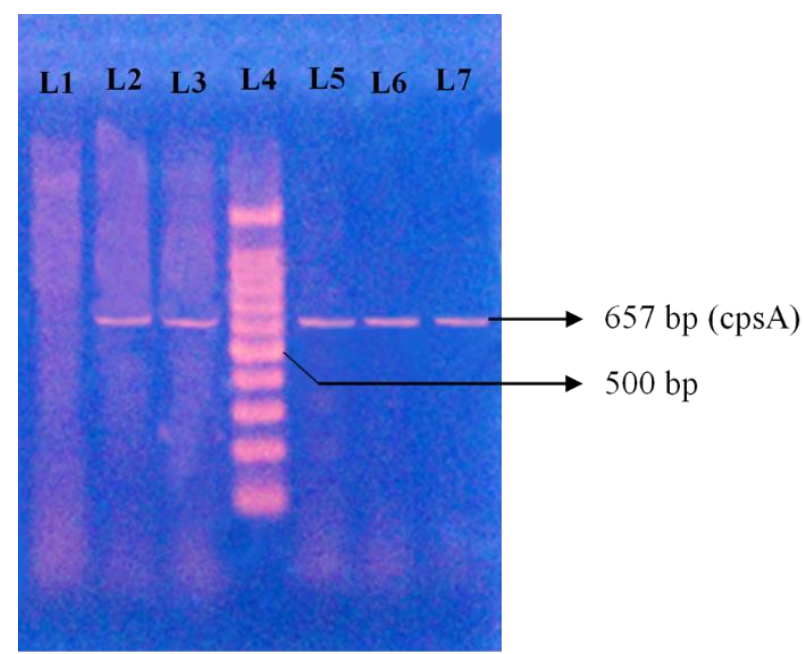

Figure II: Photograph of amplified cpsA gene of Streptococcus pneumoniae; Lane 1: negative control with DNA of Staphylococcus aureus ATCC25923; Lane 2, 3, 5, 6, 7: amplified DNA of 657 bp of cpsA gene; Lane 4: hundred bp DNA ladder

\section{Discussion}

Various factors may affect the nasopharyngeal colonization with $S$, pneumoniae. Various demographic characteristics had been described to associated with an increase in nasopharyngeal carriage of Streptococcus pneumoniae including young children ${ }^{9,10}$ family size ${ }^{11,12}$, less number of room in house ${ }^{13,14}$, low socio-economic 
condition $^{15,16}$. In the present study, all of the aforementioned demographic characteristics had been described to be associated with an increase in Streptococcus pneumoniae carriage. A study in Ehtiopia $^{13}$ reported that Streptococcus pneumoniae showed an age-related downward trend. Children belonging to the age group of $<3$ years were the most colonized, followed by those 3-5 years of age. The decline in Streptococcus pneumoniae carriage rate associated with increasing age may reflect the gradual acquisition of mucosal immunity and reduction of exposure. In the present study, carriage rare was more detected in those children who had > 5 members. In a study ${ }^{13}$ reported that, children living with siblings (family size >5) showed significantly higher Streptococcus pneumoniae carriage compared with children who do not have any siblings. This finding was similar to reports from other studies ${ }^{17,18}$ and from the present study. This is of great relevance because exposure to other children during childhood, especially to younger siblings, had been clearly associated with an increased risk for invasive and noninvasive pneumococcal diseases ${ }^{13}$. Moreover, a study by Assefa et $\mathrm{al}^{13}$ also reported significantly higher Streptococcus pneumoniae nasopharyngeal carriages rates among children who lived with their family in a house with only one room and other children. This result is consistent with the present study. A study reported that in low and lowermiddle income population, the prevalence of pneumococcal carriage was high in young children in contrast in upper-middle and high income population $(93.4 \% \text { vs } 58 \%)^{19}$. This finding is similar with the present study. Streptococcus pneumoniae carriage was more associated with low socio-economic condition, reasons might be due to low socioeconomic status causes poor, overcrowding living conditions and also causes poor nutritional status and poor nutrition lead to lower immunity which prone to colonization of Streptococcus pneumoniae.

Streptococcus pneumoniae detection rate from nasopharyngeal swab was higher by PCR than culture which might be due to the fastidious nature of the organism and low load of the organism with co-colonization that can result in false negative results. PCR can detect bacterial DNA even if the numbers of organism is too low to grow in culture ${ }^{20}$ and can detect from non-viable organisms after treatment with antibiotics ${ }^{21}$.

\section{Conclusion}

Detection rate of nasopharyngeal carriage of Streptococcus pneumoniae was relatively more including with various factors may affect the nasopharyngeal colonization with $S$. pneumoniae using both culture and PCR. Streptococcus pneumoniae is a commensal species of the human upper respiratory tract, local or systemic infections are preceded by colonization, and colonized individuals also serve as a reservoir in the community, Streptococcus pneumoniae is a major etiological agent of non-invasive infections like acute otitis media (AOM) and severe invasive diseases like community acquired pneumonia (CAP), meningitis and bacteremia. So, surveillance programs should be carried out continuously to monitor the risk factors in order to crub the problem of developing pneumococcal diseases by early stage vaccination among these risk groups.

\section{References}

1. Normark B, Tuomanen EI. The pneumococcus: Epidemiology, microbiology, and pathogenesis. Cold Spring Harb Perspect Med 2013;3:e010215

2. World Pneumonia Day. Universal Access for Pneumonia Prevention and Care, 2014

3. Gray BM, Converse GM, Dillon HC. Epidemiologic studies of Streptococcus pneumoniae in infants: acquisition, carriage, and infection during the first 24 months of life. J Infect Dis, 1980; 142: 923-933

4. Lang ALS, McNeil SA, Hatchette TF, Elsherif M, Martin I, Jason J, et al. Detection and prediction of Streptococcus pneumoniae serotypes directly from nasopharyngeal swabs using PCR. J Med Microbiol, 2015; 64: 836-844

5. Cardozo DM, Nascimento-Carvalho CM, Andrade AL, et al. Prevalence and risk factors for nasopharyngeal carriage of Streptococcus pneumonia among adolescents. J Med Microbiol, 2008;57:185-189

6. Mackenzie GA, Leach A, Carapetis JR, Fisher J, Morris PS. Epidemiology of nasopharyngeal carriage of respiratory bacterial pathogens in children and adults: cross-sectional surveys in a population with high rates of pneumococcal disease. BMC Infect Dis 2010;10:304-310

7. Rubin GR, Rizvi A, Baer A. Effect of swab composition and use of swabs versus swab-containing skimmilk- TryptoneGlucose- Glycerol(STGG) on culture or PCR-based detection of Streptococcus pneumoniae in simulated and clinical respiratory specimens in STGG transport medium. J Clin Microbiol 2008;46:2635-2640

8. Morona JK, Morona R, Paton JC. Analysis of the 5 'portion of the 19A capsule locus identified two classes of cpsC, cpsD and cpsE genes in Streptococcus pneumoniae. $\mathrm{J}$ Bacteriol, 1999; 181: 3599-3605

9. Farida H, Severin JA, Gasem MH, Keuter M, Wahyono H, Verbrugh HA, et al. Nasopharyngeal carriage of Streptococcus pneumoniae in pneumonia-prone age groups in Semarang, Java Island, Indonesia. PLoS One, 2014; 9: e87431

10. Roca A, Bottomley C, Hill PC, Bojang A, Egere U, Antonio $\mathrm{M}$, et al. Effect of age and vaccination with a pneumococcal conjugate vaccine on the density of pneumococcal nasopharyngeal carriage. Clin Infect Dis, 2012; 55: $816-824$

11. Cekmez F; Karadernir F, Tanju IA, Meral C, Pirgon O, Ozyurt M, et al. Pneumococcal serotypes recovered from health children and their possible association with risk factor in Istanbul, Turkey. Inf J Biomed Sci, 2009; 5: 101-104

12. Hadinegoro SR, Prayitno A, Khoeri MM, Safari D, Mudaliana S, Muttaquin Z, et al. Nasopharyngeal carriage of Streptococcus pneumoniae in the healthy children under five 
years old in central Lombok regency, Indonesia. Southeast Asian J Trop Med Public Health, 2016; 47: 485-493

13. Assefa, A, Gelaw B, Shiferaw Y, Tigabu Z. Nasopharyngeal carriage and antimicrobial susceptibility pattern of Streptococcus Pneumoniae among pediatric outpatients at Gondar University Hospital, North West Ethiopia. Pediatr Neonatal, 2013; 54: 315-321

14. Gebre T, Tadesse M, Aragaw D, Feye D, Mekonennen M, Byene BH, et al. Nasopharyngeal Carriage and Antimicrobial susceptibility patterns of Streptococcus pneumoniae among children under five in Southwest Ethiopia. Children, 2017;4:2734

15. Usuf H, Bottomley $\mathrm{C}$, Adcghola RA, Hall A. Pneumococcal carriage in sub-Saharan Africa: a systematic review. PLoS One 2014;9:e85001

16. Yasin RM, Zin NM, Hussin A, Nawi SH, Hanapiah SM, Wahab ZA, et al. Current trend of pneumococcal serotypes distribution and antibiotic susceptibility pattern in Malaysian hospitals. Vaccine 2011; 29: 5688-5693
17. Hill PC, Cheung YB, Akisanya A, Sankareh K, Lahai G. Nasopharyngeal carriage of Streptococcus Pneumoniae in Gambian infants: a longitudinal study. Clin Infect Dis, 2008;46:807-814

18. Regev-Yochay G, Abullaish I, Malley R, Shainberg B, Varon M, et al. Streptococcus pneumoniae carriage in the Gaza strip. PLoS One, 2012; 7: e35061

19. Richard AA, DeAntonio R, Hill PC, Roca A, Usuf E, Hoet $\mathrm{B}$, et al. Carriage of Streptococcus pneumoniae and other respiratory bacterial pathogens in low and lower-middle income countries: A systemic review and meta-analysis. PLoS One, 2014; 9: e103293

20. Rudolph KM, Parkinson AJ, Black CM, Mayer LW. Evaluation of polymerase chain reaction for diagnosis of pneumococcal pneumonia. J Clin Microbiol, 1993; 31: 2661266623

21. Wheeler J, Murphy OM, Freeman R, Kearns AM, Steward M, Lee MJ. PCR can add to detection of pneumococcal disease in pneumonic patients receiving antibiotics at admission. J Clin Microbiol, 2000; 38: 3907-3911 